\title{
Alinhamento Estratégico da Utilização da Internet e do Comércio Eletrônico: os Casos Magazine Luiza e Fleury
}

\author{
Amarolinda I. Costa Zanela Saccol
}

\begin{abstract}
Resumo
O artigo apresenta os resultados de uma pesquisa que tem por objetivo identificar como ocorre a formação de estratégias e o planejamento da utilização da Internet e do Comércio Eletrônico (CE) considerando a questão do Alinhamento Estratégico, no contexto brasileiro. Para isso, utiliza o método de Estudos de Casos Múltiplos, analisando duas empresas de referência, consideradas pioneiras na utilização da Internet e do CE de forma intensiva, no Brasil: o Magazine Luiza, no setor varejista, e o Fleury - Centro de Medicina Diagnóstica, no setor serviços. Apesar de as empresas pesquisadas pertencerem a segmentos distintos, foram encontrados diversos pontos comuns que ajudam na compreensão da questão pesquisada, indicando elementos que contribuem para o Alinhamento Estratégico da Internet/CE com a estratégia organizacional e com a estratégia de Tecnologia de Informação.
\end{abstract}

Palavras-chave: Internet; comércio eletrônico; alinhamento estratégico.

\begin{abstract}
The article presents the results from a research project that aims to identify how strategy formulation and strategic planning are done regarding the Internet and Electronic Commerce usage, taking into consideration the Strategic Alignment issue, in a Brazilian context. To reach its goal, the research applied a Multiple Case Studies Method, analyzing two benchmark companies in Internet and Electronic Commerce usage in Brazil: the Magazine Luiza, from the Retail Sector, and the Fleury - Centro de Medicina Diagnóstica, from the Health Service sector. Despite the fact that the companies belong to very distinct sectors, there are a lot of common factors that support the research question comprehension, pointing some elements that contribute to the Strategic Alignment of Internet and Electronic Commerce usage in relation to organizational strategy and Information Technology Strategy.
\end{abstract}

Key words: Internet; electronic commerce; strategic alignment. 


\section{INTRODUÇÃO}

A Internet tem-se tornado a espinha dorsal em termos de Tecnologia de Informação, seja de uso intra ou interorganizacional, como ambiente que interliga vendedores e clientes, possibilitando interação e transações em tempo real (CASTELLS, 2001; VENKATRAMAN, 2000). Considerando esta realidade, faz-se necessário compreender como ela pode de fato contribuir com a competitividade empresarial. Gascoyne e Ozcubukcu (1997) afirmam que muitas empresas se apressam em investir na Internet, sem ter clara visão do que irão fazer com as novas tecnologias. Elas não reconhecem que a Internet muda não só a forma de fazer negócios, mas também força a gestão a responder à seguinte questão: que processos e negócios podem estar na Internet, ou deveriam estar?

A literatura atual, em geral, preocupa-se com as aplicações de Internet e Comércio Eletrônico (CE) nas organizações (vide NGAI; WAT, 2002). Porém detectou-se carência, especialmente em relação à realidade brasileira, de estudos que se preocupem com a fase que antecede a prática da utilização dessas tecnologias, isto é, o seu planejamento e a formulação de estratégias de aplicação.

Assim, esta pesquisa tem como objetivo geral identificar como ocorre a formação de estratégias e o planejamento da utilização da Internet, considerando a questão do Alinhamento Estratégico do uso dessa tecnologia, no contexto brasileiro. O seu escopo abrange as diversas tecnologias relacionadas à Internet, bem como as diferentes formas de CE, incluindo o B2C (Business-to-Consumer), e o B2B (Business-to-Business). Para isso foram realizados dois estudos de caso em empresas nacionais, que são reconhecidos casos de sucesso na intensiva utilização da Internet e do CE, de forma pioneira no Brasil: o Magazine Luiza, no setor varejista, e o Fleury - Centro de Medicina Diagnóstica, no setor de serviços.

Na seqüência, é apresentada a fundamentação teórica da pesquisa. Logo após identifica-se o seu método; os estudos de caso são a seguir apresentados e são então discutidos os resultados do estudo, chegando-se às conclusões do artigo.

\section{Alinhamento Estratégico}

Inicialmente deve-se considerar o conceito de estratégia adotado neste estudo. Ele é proposto por Quinn (MINTZBERG; QUINN, 2001) e diz que estratégia é 
um padrão ou plano que integra as principais metas, políticas e seqüências de ações de uma organização em um todo coerente. Uma estratégia adequada ajuda a ordenar e alocar recursos de uma organização para uma postura singular e viável, com base em suas competências e deficiências internas relativas e mudanças no ambiente, sejam elas previsíveis ou não.

Nesse sentido, a idéia de Alinhamento Estratégico (AE) envolve a ligação e coerência entre a estratégia organizacional e a estratégia de TI (Tecnologia da Informação). Reich e Benbasat (2000, p. 82) definem Alinhamento como “o grau em que a missão da TI, objetivos e planos apóiam e são apoiados pela missão, objetivos e planos do negócio”. Luftman (1996, p. 205) afirma que “em essência, as estratégias de negócios e de TI estão alinhadas, quando os objetivos do negócio são possibilitados, apoiados e estimulados pelas estratégias de TI”. Chan et al. (1997) verificaram que empresas que possuem alto grau de Alinhamento Estratégico de TI tendem a ser mais efetivas. Na perspectiva do AE, a TI deixa de ser considerada um custo de fazer negócios e passa a ser vista como um importante recurso estratégico.

Um dos modelos de AE mais citados na literatura é o de Henderson e Venkatraman (1993). Ele identifica a necessidade de especificar dois tipos de integração entre os domínios de negócio e de TI: a adequação estratégica, que é a integração da estratégia de negócios com a estratégia de TI; e a integração funcional, que trata do link entre a infra-estrutura e processos organizacionais e a infra-estrutura e processos de TI.

É preciso considerar os elementos que facilitam ou que dificultam a obtenção do AE. De acordo com Segars e Grover (1998a), para se obter o Alinhamento é essencial que haja mútuo entendimento entre a direção da empresa e o pessoal de TI, além da participação de gestores e usuários finais de diversas áreas no planejamento de TI. Zviran (1990) indica que é fundamental que o planejamento de TI considere as necessidades e a estratégia organizacional para realizar o seu próprio planejamento. Luftman et al. (1999) também apontam fatores determinantes do AE entre negócio e TI, tais como: apoio da alta direção para a TI; equipe de TI envolvida no desenvolvimento de estratégias organizacionais; equipe de TI que entende o negócio e projetos de TI corretamente priorizados. Luftman (2000) aponta um modelo para avaliação do grau de maturidade do AE. Essa maturidade envolve um relacionamento em que a área de TI e as demais criam e adaptam as suas estratégias de forma conjunta.

Entre outros referenciais importantes sobre AE estão o de Luftman, Lewis e Oldach (1993), que utilizaram o modelo de Alinhamento Estratégico de Henderson e Venkatraman (1993) e detalham casos de sua aplicação. Kearns e Lederer 
(2001) apresentaram um modelo de AE que aponta vários elementos importantes que o favorecem, tais como a participação do CIO (Chief Information Officer) no planejamento de negócios e a intenção de utilizar a TI para obter vantagem competitiva. Já Brodbeck e Hoppen (2000 e 2002) estudaram a questão do AE em empresas brasileiras, e propõem um modelo estendido, no qual o AE é considerado na formulação e também no processo de implementação dos planos de negócio e de TI.

\section{Formulação de Estratégias e Planejamento da Utilização da INTERNET E do ComÉrcio Eletrônico}

A Internet teve a intensificação de sua utilização com fins comerciais nos anos 90 e trouxe consigo outras possibilidades, como as Intranets, ou redes corporativas, e redes do tipo Extranet, que ligam as Intranets de parceiros de negócio, via Internet (TURBAN et al., 1999). Com isso, intensificou-se a utilização do Comércio Eletrônico (CE) que, neste trabalho, segue a definição de Turban et al. (1999): ele refere-se ao processo de comprar, vender ou trocar produtos, serviços e informações via redes de computadores, incluindo a Internet. É preciso enfatizar que o CE é visto de forma ampla, não envolvendo somente transações de compra e venda, mas todo tipo de troca de informações e de virtualização dos processos de negócio da empresa. Com isso, Turban et al. (1999) equiparam o conceito de CE ao de $e$ business, termos que serão utilizados de forma equivalente neste artigo.

Venkatraman (2000) aponta elementos-chaves na estratégia de operações de uma organização na Internet. O principal deles envolve uma proposição de valor para os clientes, o que pode implicar novo modelo de negócios. Condições estruturais precisam ser consideradas, como, por exemplo, diferenciar ou integrar ao atual negócio as decisões operacionais e financeiras relativas a ponto.com, as fontes de recurso para a utilização da Internet e a infra-estrutura operacional necessária. Kalakota e Robinson (2001, p. 26) advertem que "a decisão de desenvolver uma arquitetura de $e$-business é uma decisão de negócio, não uma decisão técnica”. Neste sentido, eles propõem elementos-chaves para serem considerados ao se iniciar as atividades de $e$-business: compreender o consumidor, seus valores e tendências de relacionamento; compreender as tendências de TI e da cadeia de suprimentos, as regras de competição e as competências essenciais da própria empresa. Porter (2001) realiza uma análise abrangente das questões estratégicas do uso da Internet, com foco no seu impacto não só sobre a vantagem competitiva de uma empresa, mas também sobre a estrutura das indústrias, apontando aspectos positivos e negativos daí decorrentes. 
Hackbarth e Kettinger (2000) estudaram a construção de uma estratégia de $e$ business e identificaram três diferentes níveis de desenvolvimento. O primeiro nível é o de experimentação, quando a empresa não tem ainda uma estratégia de $e$-business definida; no segundo estágio, de integração, a estratégia de $e$ business serve para apoiar a estratégia corporativa adotada. Já no terceiro estágio, de transformação, a estratégia de $e$-business passaria a ser uma das condutoras da estratégia organizacional, interligando a empresa a clientes, fornecedores e parceiros. Comparando-se esses três estágios com o modelo de Alinhamento de Henderson e Venkatraman (1993), pode-se dizer que o e-business pode ser tanto a ferramenta de execução de uma estratégia preestabelecida, isto é, primeira perspectiva de Alinhamento, como um condutor de mudanças e novas estratégias da organização.

Cronin (1996) propõe certa matriz de posicionamento para a análise do potencial de aplicações da Internet, considerando necessidades corporativas internas, meios externos de conectividade dos consumidores, forças competitivas e desenvolvimento técnico. A partir da consideração desses fatores, têm-se várias abordagens de estratégia competitiva: busca de redução de custo/eficiência; melhoria de desempenho; penetração de mercado ou transformação de produtos. De forma semelhante, Amit e Zott (2001) destacam que a empresa precisa estabelecer a estratégia de Internet/CE, visando a uma criação de valor, tanto para si quanto para seus clientes ou parceiros. Eles identificaram 4 principais fontes de criação de valor pela utilização do e-business: (1) eficiência; (2) novidade; (3) complementaridade entre vendas e serviços on-line e off-line; e (4) aprisionamento, lock-in, que envolve a fidelização de clientes e parceiros de negócios.

Vários autores têm procurado propor modelos para a criação de estratégias de CE. Turban et al. (1999) apontam um ciclo de planejamento estratégico do CE semelhante aos modelos tradicionais de planejamento, que envolve análise da indústria e análise competitiva, formulação da estratégia, implementação e avaliação do desempenho, reiniciando-se o ciclo. Rozwell (2001) apresenta uma matriz, cujas aplicações de Internet/CE devem ser consideradas em dois eixos: contribuição para desempenho superior da empresa e alcance de objetivos versus nível de risco envolvido. Várias possibilidades são classificadas nessa matriz, desde a automatização de processos simples já existentes, com baixo risco e baixa contribuição, até a redefinição de negócios. Reilly et al. (2001) apresentam alguns passos que ajudam na priorização de projetos de $e$-business. Esses passos consideram os processos críticos da organização e o risco envolvido nas mudanças, o tempo de payback, a complexidade de cada projeto, assim como o impacto interno e externo sobre a organização. 
Raghunathan e Madey (2001) elaboraram um gerador de estratégias em CE, baseados no Gerador de Opções Estratégicas de Wiseman (1985). Papp e Fox (2002) estão desenvolvendo uma pesquisa que investiga a questão do AE, utilizando o modelo de Henderson e Venkatraman (1993) em empresas da Internet. Dadas as restrições de espaço, esses modelos são aqui mencionados de forma breve, porém foram considerados pela pesquisa.

\section{Método de Pesquisa}

O método utilizado é o de Estudo de Casos Múltiplos (YIN, 2001). Conforme Benbasat et al. (1987), o estudo de casos múltiplos é desejável, quando a intenção da pesquisa é o conhecimento mais profundo de uma realidade, para a construção de proposição teórica. As empresas pesquisadas são o Magazine Luiza e o Fleury, Centro de Medicina Diagnóstica. Essas organizações foram escolhidas por serem nacionais e notoriamente casos de sucesso na adoção da Internet/CE, por utilizarem intensamente essas tecnologias de forma pioneira em seus setores de atuação no Brasil. Einsenhardt (1989) indica que, dado o limitado número de casos que podem ser acessados em Estudos de Casos Múltiplos, tem sentido escolher casos extremos, cujo o processo de interesse é claramente observável.

Em estudo de caso, é imprescindível que os dados sejam coletados em diferentes fontes. Para isso, com base em Reich e Benbasat (1996), foram realizadas entrevistas com executivos de áreas de negócios e executivos de TI/SI, responsáveis pelas questões relacionadas à Internet/CE. No Magazine Luiza foram entrevistadas 6 pessoas: um gestor da área Comercial, um Gerente de Televendas, uma Assessora da Superintendência (que trabalha na coordenação do Planejamento Estratégico da empresa), um Gerente de Loja Virtual, um Gerente de TI e um Gerente de Comércio Eletrônico. No Fleury foram entrevistadas 5 pessoas: o Diretor de TI, o Webmanager, o Diretor de Atendimento, a Diretora Comercial e de Novos Negócios e o Diretor Superintendente. Para a realização das entrevistas foram utilizados roteiros estruturados, elaborados a partir de instrumentais já existentes para avaliação do Alinhamento Estratégico, apresentados pelos seguintes autores: Brodbeck e Hoppen (2000); Brown e Magill (1994); Chan et al. (1997); Reich e Benbasat (1996); Segars e Grover (1998a); Segars et al. (1998b); Zviran (1990). Esses instrumentais foram adaptados para tratar das questões relativas a Internet e CE. Cada roteiro possuía um bloco de perguntas gerais, aplicadas a todos os entrevistados, e outro bloco com questões específicas relativas à área de atuação de cada um deles. 
Também foi acessada a documentação do planejamento de negócios e de TI, de curto e de longo prazo, propostas e projetos. No Magazine Luiza foi acessado os seguintes documentos: organograma da empresa, documentação referente ao Planejamento Estratégico da organização, planejamento da área de TI e de CE e dados provenientes do web site da empresa. No Fleury os documentos foram: documentação referente ao Planejamento Estratégico da organização, descrição geral do funcionamento da área de TI e dados provenientes do web site da empresa. Além disso, também ocorreu a observação direta: no Magazine Luiza foram realizadas visitas à sede da empresa, em Franca/SP, onde se pôde observar pessoalmente o funcionamento dos setores do escritório de gestão, loja central e uma das Lojas Virtuais da rede. No Fleury foram realizadas visitas à sede da empresa, em São Paulo/SP, onde se pôde observar pessoalmente o funcionamento dos setores de gestão e do setor de processamento dos exames.

Foram ainda acessadas bibliografias sobre as empresas pesquisadas, uma vez que ambas são empresas sobre as quais há uma diversidade de reportagens disponíveis na imprensa brasileira e mesmo em estudos acadêmicos de outras áreas, como Marketing e RH. Essas fontes contribuíram para corroborar parte dos dados primários levantados. Os dados foram coletados no período de abril a novembro de 2002. As entrevistas foram gravadas e transcritas, realizando-se posteriormente a análise de seu conteúdo. Todas as outras fontes de dados foram igualmente consideradas na análise.

Na seqüência, os dois casos são analisados, chegando-se depois às conclusões do estudo.

\section{O Caso Magazine Luiza}

O Magazine Luiza, uma loja de departamentos de capital nacional, iniciou suas atividades em 1957. Seu faturamento em 2003 foi de R 920 milhões, empregando cerca de 3.200 pessoas, em 174 lojas, 137 convencionais e 37 virtuais, incluindo o site web. O CE representa cerca de $10 \%$ do seu faturamento, sendo utilizado em diferentes canais como estes: Lojas Virtuais; Site Web; Televendas; Lounges e Quiosques.

As Lojas Virtuais apresentam conceito inovador, no qual o Magazine Luiza foi pioneiro. Nessas lojas não há produtos físicos, as vendas são realizadas em células, com um computador no qual são demonstrados os produtos, pelos vendedores, e realizadas todas as demais operações: cadastro, análise de crédito, etc. O alvo dessas lojas são cidades pequenas ou bairros de grandes cidades. 
Seu custo é cerca de $15 \%$ do custo de uma loja tradicional, tendo em média $150 \mathrm{~m}^{2}$, ao invés de cerca de $800 \mathrm{~m}^{2}$. É parte do conceito de Lojas Virtuais a interação com a comunidade local. Cada loja possui um Centro de Eventos, no qual são oferecidos diversos cursos, realizam-se encontros da comunidade; há acesso gratuito à Internet e posto bancário, atraindo e oferecendo serviços adicionais aos clientes.

Já o site web do Magazine Luiza (http://www.magazineluiza.com.br) é a loja com o maior volume de vendas de toda a rede. Juntamente com o site comercial está o Tia Luiza, site com informações e dicas de uso sobre os produtos comercializados. O canal de Televendas serve basicamente para apoiar o comércio realizado via web.

Os Lounges e Quiosques são outros canais em que se utiliza a Internet. Um Quiosque possui apenas um ou dois microcomputadores, com vendedores que apresentam os produtos via catálogo eletrônico. Já os Lounges exibem alguns produtos físicos específicos em ilhas montadas normalmente em Shopping Centers. O Magazine Luiza também realiza o CE B2B junto a alguns de seus principais fornecedores; e, quanto ao $\mathrm{CE}$ intraorganizacional, realiza atividades de ensino a distância via Internet, principalmente para treinamentos de vendas. O e-mail é utilizado intensivamente na comunicação entre filiais e destas com a matriz.

Planejamento Estratégico Organizacional, Planejamento de TI e Planejamento da Utilização da Internet e do CE na Empresa. O processo de Planejamento Estratégico (PE) da empresa ocorre formalmente desde 1990. Ele tem início a partir da geração de um intento estratégico, com horizonte de longo prazo, de 3 a 5 anos. A partir desse intento são definidos os Fatores Críticos de Sucesso para o seu alcance e as ações que vão ser realizadas. Esses elementos são estabelecidos para a empresa como um todo, desdobrando-se para cada área funcional. É feito o alinhamento das ações para a efetivação do plano. Ao longo do ano são realizadas reuniões mensais de monitoramento do PE, em que cada área apresenta o status do que foi planejado, assim como necessidades de apoio de outras áreas.

O Planejamento da área de TI segue essa mesma metodologia. Ela é, atualmente, a área de apoio mais importante para as demais. As necessidades de cada área são negociadas abertamente, verificando-se as demandas gerais existentes e priorizando-as com base nos interesses da empresa. A área de TI também apresenta à organização novas tecnologias e ferramentas. Essas são discutidas em conjunto e só passam a ser adotadas após estudo que mostre claramente a sua relação custo-benefício. 
Desde o início das ações de CE, a área de TI atua como consultoria técnica, apoio à escolha de fornecedores etc. Porém foi designada uma equipe específica para trabalhar o CE, na área Comercial, o que não é visto como problema, na opinião do gestor de TI e do gestor de CE. Uma das razões para a separação foi que a estrutura interna de pessoal e a infra-estrutura de TI não tinham condições de absorver as novas atividades relativas ao CE. Para se ganhar agilidade, foi dada autonomia decisória à área de CE e alocados recursos externos para atender às suas necessidades. No dia-a-dia, as duas áreas trabalham em cooperação.

Histórico de adoção da Internet e do CE, e seu Alinhamento com a Estratégia Organizacional. Para compreendermos a questão do Alinhamento Estratégico da utilização da Internet e do CE na empresa, é necessário resgatar o histórico de adoção dessas práticas.

As ações de Comércio Eletrônico começaram em 1991. Na época foi lançada a seguinte questão estratégica: Como expandir a rede de lojas com baixos custos? Em resposta a essa pergunta, foi criada, em 1992, a primeira Loja Virtual, na época chamada de Loja Eletrônica, que nasceu no departamento comercial, a partir do trabalho de grupos de estudo.

Na época, os recursos multimídia tinham alto custo. Assim, a primeira loja virtual trabalhava com catálogos impressos de fornecedores, pôster e fitas de vídeo. Um dos entrevistados relata a experiência: "Então quando uma pessoa chegasse na loja e dissesse que estava interessada em um fogão, por exemplo, o vendedor pegava a tabelinha e olhava o produto e sua posição na fita. Pegava a fita, apertava o botão, corria, achava; então parava e daí mostrava. Assim se vendia muita coisa. Isso foi utilizado por uns 6 meses”.

Estava implantado novo conceito na empresa: o de vender o produto, sem necessariamente o cliente tocá-lo. Essa era uma proposta totalmente ousada para a época, e a relação da empresa com as comunidades locais foi essencial para viabilizá-la. Diversas formas de divulgação das Lojas foram adotadas, junto a escolas e centros comunitários, trabalhando-se o conceito de compra virtual, além do próprio Centro de Eventos, instalado nas Lojas, que atrai a comunidade. Não houve pesquisa junto aos clientes para verificar a aceitação dessa iniciativa. De acordo com um dos entrevistados: “a superação de não tocar o produto era minimizada devido à credibilidade da empresa”.

Foram necessários cerca de dois anos para consolidar a Loja Virtual, pelo alto custo da tecnologia multimídia. Somente a partir de 1994/1995, foi possível integrar um catálogo eletrônico ao software de venda das lojas. Estas foram criadas quando a Internet era uma tecnologia quase inacessível no Brasil, principalmente 
ao público-alvo da empresa. Porém estava lançado o intuito estratégico de atuar em multicanais; as Lojas Virtuais foram a ferramenta para colocar essa estratégia em prática.

Já em 1998, foi ao ar o site web da empresa, visando somente à divulgação institucional. Em 1999, ele começou a ser utilizado para vendas. Foi apontado por um dos entrevistados que atuar no CE via web, em princípio, não estava previsto no Planejamento Estratégico da empresa: "Mas daí o que aconteceu, como começou a vir aquela febre Internet, Internet, Internet, começamos a pensar: isso é um canal de vendas e nós não podemos ficar fora (...) A princípio então não estava planejado; com o surgimento desta febre e a necessidade de se criar o multicanal (e o site fazia parte), não tinha como fugir, aí a empresa resolveu desenvolver um projeto (...) O planejamento estratégico do site era feito bem localmente naquela área [comercial], foi incorporado depois no planejamento estratégico [da empresa]”.

Ao contrário das Lojas Virtuais, por meio das quais se buscou uma tecnologia para viabilizar a estratégia, a atuação na web foi quase mandatária, isto é, a nova tecnologia se tornou imperativa para a empresa, que adotou por princípio operar em multicanal. Logo, a TI levou a um novo meio de atuação. A perspectiva de Alinhamento, neste caso, se aproxima da de Potencial competitivo (HENDERSON; VENKATRAMAN, 1993). De acordo com essa perspectiva, exploram-se as capacidades emergentes da TI para impactar novos produtos e serviços, havendo adaptação da estratégia de negócios via capacidades emergentes da TI.

Contudo a empresa foi bastante céptica e cautelosa em relação aos investimentos na web, como costuma ser em relação a qualquer investimento em TI. De acordo com um dos entrevistados: "Quando muitas empresas em 1999, principalmente em 2000, explodiram aí com lançamentos (e muitas delas hoje nem existem mais), foi aquele "boom", aquela coisa toda. Logo a gente foi muito... conservador, vamos dizer assim, sabendo que o negócio iria evoluir (...) Então em 2001 aí sim nós fomos colocar realmente uma mídia mais forte, colocamos em revistas, em jornais etc. Então nesse momento foram as estratégias para não 'torrar dinheiro', se divulgou quando se tinha certeza da viabilidade do negócio”.

Além do CE via Lojas Virtuais e site web, intensificaram-se na seqüência outras ações, como o Televendas, os Lounges e Quiosques, e mesmo o CE $B 2 B$. Com a tecnologia, foi possível ir ao lugar onde o cliente está e efetivar os múltiplos canais de negócios. A partir daí as iniciativas relacionadas ao Comércio Eletrônico procuraram ser cada vez mais integradas. 
Processo de aprendizado e planejamento dinâmico. De acordo com os entrevistados, o processo de adoção da Internet baseou-se na prática, no aprender fazendo. A estrutura e a forma de atuação foram sendo pensadas durante o processo de adoção. Quanto à forma como foram estabelecidas as prioridades de ferramentas de CE, foi colocado pelos entrevistados que ela se deu de forma natural: começouse com as Lojas Virtuais, em 1992; em 1998 ficou clara a oportunidade de atuação na web, e também a possibilidade de utilizar a Internet para interligação com fornecedores. De acordo com um dos entrevistados: "Foi uma sinergia... Uma coisa foi puxando a outra. A gente já tinha uma evolução, os fornecedores já conheciam a nossa experiência nisso; então já foi muito mais fácil a aceitação...”

Em relação ao CE via site web, cabe destacar que já havia infra-estrutura, que foi decisiva: a existência de uma central de multimídia, montada para as Lojas Virtuais, em que todos os produtos comercializados são filmados, fotografados e digitalizados em diversos ângulos, com a elaboração da sua ficha técnica. A empresa já tinha, portanto, "um arsenal de informações e de imagens, possibilitando uma entrada, vamos dizer assim, muito amena na Internet”. Outra vantagem é que ela já possuía a estrutura de entrega direta ao consumidor, a que foi adicionada uma parceria, com operador logístico de entregas em nível nacional.

A empresa também definiu as diversas formas de pagamento via site web, com o cuidado de não reduzir a margem das suas operações. Uma das maiores preocupações é a integração constante entre os diversos canais. O objetivo é que o cliente sempre veja o Magazine Luiza como uma única entidade. Para isso, utiliza-se a mesma linguagem, padrão de comunicação, campanhas e promoções em todos os canais, apenas adaptando a mensagem a cada mídia. É reconhecido que há uma competição natural entre esses canais; afinal, cada um deles possui suas próprias metas de vendas. Esse conflito procura ser amenizado por meio da busca de sinergia: um exemplo disso são demonstrações de produtos realizadas em lojas convencionais às quais se enviam convites a clientes do site web .

As tendências de CE estão sempre sendo observadas pela empresa, tanto pela equipe de CE quanto pela de TI. Uma das últimas novidades foi a parceria com a rede Blockbuster, junto à qual se instalaram Quiosques para a venda de equipamentos de vídeo e áudio.

\section{O Caso Fleury - Centro de Medicina Diagnóstica}

O Fleury - Centro de Medicina Diagnóstica - é uma empresa nacional, fundada em 1926. Possui cerca de 1.500 funcionários e oferece serviços ambulatoriais 
de medicina diagnóstica, com aproximadamente 2.000 tipos de exames. Além de atender aos clientes finais, o Fleury também presta serviços a outros laboratórios no País, atende a alguns hospitais e a cerca de 150 empresas de seguro saúde. A empresa atua na grande São Paulo e está em expansão para outras cidades, com um total de 16 unidades de atendimento. A concorrência no seu setor de atuação é acirrada.

A empresa utiliza a Internet de forma intensiva. No B2C, em seu site (http://www.fleury.com.br), ela oferece conteúdo e serviços aos clientes. É possível obter todas as informações sobre os exames e agendá-los, solicitar coleta domiciliar, assim como acessar os resultados de exames, que podem ser recebidos também via e-mail, e histórico pessoal dos últimos 8 anos. Os médicos, laboratórios e hospitais associados também podem acessar resultados de exames, mediante autorização de cada paciente. Para os médicos, o site oferece uma série de publicações técnicas, além de educação multimídia, manuais, e também assessoria para resoluções de dúvidas, via e-mail. A empresa não comercializa seus serviços via site web e também não torna disponíveis nele anúncios publicitários, por razões éticas.

No B2B, além do site web, a empresa utiliza uma Extranet, que a interliga com alguns hospitais específicos e também com alguns laboratórios parceiros. Via EDI/Internet a empresa realiza compras corporativas, além de possuir um sistema de EDI (Eletronic Data Interchange) para interagir com empresas de planos de saúde, na realização do processo de eligibilidade, pelo qual se certifica a validade do plano de saúde dos clientes, recursos disponíveis, situação de crédito etc. Também se utiliza o EDI para envio e recebimento de cobranças. No CE intraorganizacional, a Intranet é uma ferramenta de suporte para os processos e comunicação interna entre as unidades, além de ser uma ferramenta de capacitação dos funcionários.

Planejamento estratégico organizacional, planejamento de TI e planejamento da utilização da Internet e do CE na empresa. A empresa realiza anualmente um Planejamento Estratégico formal, atualizado regularmente. Nesse planejamento são analisados os cenários externos, realizadas pesquisas de tendências junto ao mercado, clientes internos e externos. Esse planejamento envolve todas as áreas da empresa, o Conselho de Administração e conta também com um consultor externo que acompanha o processo.

No PE são definidas 4 macroestratégias organizacionais, referentes aos seguintes setores: Linha de Negócios, Comunicação, Gestão e Processos. Para se trabalhar cada uma delas é formada uma equipe com pessoas de diferentes áreas da empresa. Para cada macroestratégia verifica-se a situação atual, as 
necessidades do mercado e da empresa. A partir disso elas são desdobradas e são criados projetos de ação para a sua execução. Esses projetos são submetidos à avaliação do comitê executivo e passam, ao longo do ano, por fiscalizações em reuniões mensais que envolvem o comitê executivo, diretorias setoriais e responsáveis específicos por cada projeto.

O planejamento da área de Informática/TI ocorre no contexto do planejamento estratégico da organização. Além disso, a diretoria de TI participa de reuniões semanais do comitê executivo da empresa, onde são alinhados os objetivos e ações da empresa e da área. A área de TI está constantemente envolvida em projetos de outras áreas, como é o caso de projetos da área de Atendimento, que envolvem seleção e adoção de ferramentas para a melhoria de processo. As prioridades são decididas de maneira conjunta entre as áreas.

As estratégias e ações relacionadas à Internet estão incorporadas ao planejamento organizacional e são discutidas no chamado “Grupo de Internet”, que consiste em uma equipe multidisciplinar que planeja a utilização dessa tecnologia, integrando informações de projetos de todas as áreas, planejando e priorizando melhorias e novos serviços a serem oferecidos. Esse Grupo é formado por este elenco: Webmanager, coordenadora; dois representantes do Departamento Comercial; dois do Departamento de Marketing; três do Setor de Atendimento; duas pessoas da área de Informática/TI; dois médicos do centro de diagnóstico; uma pessoa do setor de análises clínicas e eventuais convidados, de diferentes áreas, conforme o assunto a ser tratado. Cada membro do Grupo e sua respectiva área têm papel específico. O Grupo se reúne quinzenalmente para discutir projetos, prioridades e cronograma de trabalho. Todos os investimentos e ações futuras em relação ao site são discutidos nesse Grupo. Como se pode perceber, o planejamento das ações relacionadas à Internet e CE ocorre de forma coletiva e está integrado ao planejamento organizacional como um todo e ao planejamento de TI. Isso garante o seu alinhamento em relação aos objetivos e prioridades organizacionais.

Histórico de adoção da Internet e do CE, e seu Alinhamento com a Estratégia Organizacional. De acordo com os entrevistados, tudo teve início com a febre da Internet, por volta de 1994-1995. Naquela época, passou-se a levantar informações sobre as possibilidades dessa nova tecnologia. Foram ouvidos profissionais externos, professores de centros de estudo de renome e visitaramse empresas responsáveis por portais na área de saúde. Após essa exploração, a Internet foi considerada, primeiramente, como uma nova forma de comunicação com o cliente, investindo-se em mecanismos de comunicação no site, criado em 1996. Naquela época, ele ficou a cargo da área de Marketing, passando depois para a área de Informática/TI, onde foi composta uma equipe técnica 
destinada a cuidar especificamente desse setor, criando-se também o Grupo de Internet.

Foi ressaltado nas entrevistas que as aplicações da Internet foram bastante discutidas internamente. Dessa discussão participaram, na época, o Superintendente da empresa, o Gerente Comercial, o Diretor de TI, o corpo de Conselheiros e as demais pessoas envolvidas. O trabalho em equipe nesse planejamento foi ressaltado por um dos entrevistados: "Eu acho que foi muito importante ter pessoas só pensando nisso, formar um grupo, formar as pessoas, formar coisas, estar discutindo isso de forma clara e funciona muito bem hoje em dia. A gente trabalha muito com grupos multidisciplinares, o pessoal de outras áreas, e daí você consegue com isso, aquela história: alinhar dentro das estratégias da empresa”.

Em 1997, de forma pioneira, a empresa passou a tornar disponíveis os resultados de exames via web a um grupo específico de médicos, em uma experiência piloto. Com isso, ela buscava reduzir o tempo de entrega que consumia cerca de 4 a 5 dias via correio tradicional. Foi possível criar a infra-estrutura e testar esse novo processo. Aproveitando essa experiência, em 1998 foi implantada a entrega de resultados de exames aos clientes finais, via site web. Aprimorando ainda mais a sua base instalada, a empresa passou, na seqüência, a oferecer aos médicos o histórico dos resultados de seus clientes de forma agregada, isto é, cada médico possui um código pelo qual acessa os resultados de seus diversos pacientes.

Aliada à idéia de oferecer um serviço adicional a clientes e médicos, estava também a intenção de se ganhar eficiência no processo de retirada de resultados de exames. De fato, houve uma redução significativa no custo de disponibilização de resultados. Os ganhos de eficiência não se deram somente na interação com o cliente final, mas também com as demais empresas que se relacionam com o Fleury, como laboratórios associados e planos de saúde. A retirada de resultados de exames por médicos no site evoluiu de cerca de 5.000 acessos em agosto de 2000 para quase 14.000 acessos em agosto de 2002. Em 2000, cerca de 23\% dos acessos a resultados de exames ocorriam via web, contra 44\% em 2002.

Em 2000, os clientes passaram a poder agendar exames em tempo real, via site. As ferramentas de CRM (Customer Relationship Management) ajudam a consolidar o banco de dados com informações precisas sobre as características de cada cliente, agilizando e personalizando o atendimento. Com isso, de acordo com Amit e Zott (2001), a empresa obtém o chamado lock-in (aprisionamento) do consumidor, no sentido de que suas iniciativas estimulam a fidelização de clientes e parceiros.

Ser pioneira na utilização das ferramentas de comunicação e transação via Internet era também ser coerente com a imagem do Fleury de uma empresa 
usuária de tecnologia de ponta. De acordo com um dos entrevistados: "Nós somos uma empresa que tem uma marca forte, uma empresa de ponta, tecnologias, esse tipo de coisa, então ser um benchmark na área de TI, na área de $e$-business seria também uma coisa interessante para a marca Fleury, porque o nosso cliente gosta muito disso, ele gosta de chegar e ter coisas novas acontecendo, ter alguma coisa que funciona muito bem, ter essa imagem de ponta”.

O site também contribuiu para o fortalecimento da imagem da empresa junto à classe médica. Na visão da empresa, a assessoria aos médicos é um diferencial de alto valor agregado que se tornou mais visível e acessível com os diversos recursos disponíveis no site.

Processo de aprendizado e planejamento dinâmico. Foi colocado que não houve um planejamento prévio e formal de todos os passos adotados em relação à utilização da Internet. A empresa não realizou pesquisas prévias junto aos clientes para alimentar o planejamento de suas ações de CE. A cada avanço foi sendo avaliada a receptividade dos clientes e empresas parceiras, percebendose a adesão e incentivando-se o uso de forma gradual.

Para que a comunicação com o cliente e a prestação de serviços via Internet se consolidassem, foi necessário grande aprendizado em toda a empresa, especialmente pelo cuidado necessário para a disponibilização de informações sobre resultados de exames, já que essas informações são de propriedade de cada cliente. Logo, as iniciativas de CE foram cuidadosamente planejadas em relação à confiança e privatividade dos dados, aplicando-se nisso as mais avançadas tecnologias de criptografia. Nenhuma aplicação de CE foi colocada em prática sem que essas condições estivessem garantidas. O processo de desenvolvimento de funcionalidades do site envolveu erros e acertos, e muito aprendizado. Para disponibilizar imagens dos resultados de exames no site, por exemplo, foram necessários dois anos de intenso trabalho na busca de um sistema de captura de imagens que atendesse às expectativas e que permitisse a manipulação de arquivos extensos em um período de tempo aceitável.

Os investimentos realizados na utilização da Internet foram muito ponderados. Embora eles não tenham sido planejados de forma rigorosa, mas incremental, as decisões de investimentos em TI na empresa são sempre pautadas pela busca de retorno concreto para a melhoria de serviços e eficiência. De acordo com um dos entrevistados: "a grande discussão agora é que você precisa ter todo um retorno sobre seu investimento, não dá mais para você investir nessa área [TI] sem ter retorno a fundo (...) não existe mais aquela história do pacto: "não, você precisa investir três milhões, quem não entrar nisso está perdido...”. 
Além de trazer ganhos de eficiência e de satisfação dos clientes, a Internet é vista como ferramenta que torna ainda mais visível os diferenciais competitivos da empresa. Porém todos os entrevistados se mostraram cientes de que as inovações via Internet são facilmente imitáveis e que, para garantir a liderança, é preciso inovar a todo o momento. Um deles destacou que: “A diferença da Internet é que qualquer coisa que você faz, no dia seguinte alguém pode copiar (...) É preciso sempre inovar para estar à frente da concorrência. Agora oferecemos resultados de exames via $e$-mail... Futuramente comunicação via celular etc. (...) A gente sempre tem um lançamento de alguma coisa”.

Verificou-se que, ao ser a primeira a lançar mão da tecnologia para atender aos seus clientes de forma mais ampla e diferenciada, a perspectiva de alinhamento adotada foi a de Potencial competitivo (HENDERSON; VENKATRAMAN, 1993). Nesta perspectiva de AE a empresa explora as capacidades emergentes da TI para impactar novos produtos e serviços (escopo de negócios), influenciando os atributos-chaves da estratégia.

\section{Conclusões}

Apesar de as empresas pesquisadas pertencerem a segmentos de mercado muito distintos, é possível encontrar uma série de pontos comuns que ajudam a compreender a questão do Alinhamento Estratégico verificado entre a estratégia organizacional, a estratégia de TI e a estratégia de utilização da Internet/CE.

Verificou-se que o planejamento da utilização da Internet, especialmente do site web, nasceu de forma paralela ao planejamento organizacional, incorporando-se a ele posteriormente. Em ambas as empresas, esse planejamento ocorre atualmente de forma integrada ao planejamento organizacional e ao planejamento de TI, sendo realizado de maneira coletiva, com a participação de diferentes áreas da empresa. Ele não é visto como planejamento de tecnologia, mas como planejamento de negócios, que se relaciona diretamente à estratégia organizacional. Nesse sentido, Rozwell (2001, p. 01) indica que a empresa tem de criar um plano coerente para o seu crescimento e se certificar de que o e-business está incorporado a ele, já que ele não é fim em si mesmo, mas meio.

Ambas as empresas fizeram uso da Internet e do CE de forma inovadora, com foco centrado no cliente e ao mesmo tempo buscando eficiência nas suas 
operações, redução de custos e simplificação de processos. Elas procuraram explorar as diferentes fontes de valor geradas pelo $e$-business, que são apontadas por Amit e Zott (2001): complementaridade na oferta de produtos e serviços, novidade, aprisionamento (lock-in), fidelização de clientes e parceiros, além da redução de custos e eficiência nas suas operações.

É interessante notar que nenhuma delas realizou pesquisas prévias para verificar a aceitação de suas iniciativas pioneiras em CE, e ambas venceram barreiras. O Magazine Luiza foi pioneiro na criação das Lojas Virtuais, que vieram a ser uma forma de CE aplicada junto a populações em geral com baixo acesso/utilização da Internet. Foi feito todo um trabalho de aproximação junto às comunidades em que a empresa atua, visando a gerar familiaridade com essa nova modalidade de negócios. O Fleury foi pioneiro no seu segmento, até mesmo em nível mundial, já que trata com informações de extremo valor e sigilo, tendo de vencer as barreiras para utilizar o CE de forma segura e que ganhasse a confiança e a adesão de seus clientes e parceiros. Para isso as duas empresas contaram com uma imagem de credibilidade, seriedade e qualidade junto à comunidade e clientes, anterior à atuação na Internet/CE. Elas souberam aproveitar esses diferenciais e sua forte orientação ao mercado nas novas operações. Isso é corroborado por Jackson et al. (2002), que investigaram a questão da estratégia de CE e o desempenho corporativo, identificando que empresas com forte orientação ao mercado com relação ao CE, e que lhe atribuem valor estratégico tendem a obter melhor desempenho.

Outro ponto comum verificado foi a simplicidade nas ações e comunicação com o público e preservação de uma identidade única. O Fleury preservou a interação do atendimento pessoal com o site, não criando uma unidade separada para cuidar das ações de CE. De forma análoga, o Magazine Luiza procura integrar seus diversos canais e manter um padrão de comunicação único perante os clientes. Como apontam Gulati e Garino (2000), um dos fatores de sucesso na Internet é a integração de negócios virtuais com os tradicionais.

Também se verificou, nas empresas, uma postura realista, segundo a qual os investimentos em TI e CE visam a resultados concretos. Cada investimento deve atender à estratégia organizacional, agregando valor ao cliente ou revertendo em eficiência nos processos e redução de custos. Ambas as empresas são bastante cépticas em relação a modismos de TI, e analisaram com cautela a febre da Internet, no início de sua utilização.

Outro elemento essencial é que ambas as empresas souberam obter sinergia em suas ações de utilização da Internet/CE e aproveitar o aprendizado obtido, de forma incremental. Elas aproveitaram bases tecnológicas e de dados já instaladas 
para oferecer novas funcionalidades de Internet/CE. Da mesma forma, nenhuma delas realizou um planejamento rígido e formal, mas sim incremental. O aprendizado se deu de forma coletiva, envolvendo diversas áreas de negócio. Kalakota e Robinson (2001) indicam que um planejamento incremental, onde a empresa pode, através de mecanismos de feedback eficientes, ir aos poucos verificando as ações nas quais obtém ou não sucesso nas iniciativas de $e$-business é adequado, dado o ambiente mutável de negócios. Da mesma forma, Audy, Lederer e Bratcher (2000) destacam a questão da aprendizagem organizacional envolvida no planejamento de TI e de Sistemas de Informações, que foi também verificada nos casos estudados.

Finalmente, verificou-se que ambas as empresas buscam inovação constante nas ações de Internet/CE, uma vez que nesse campo, cada iniciativa é facilmente imitável e para manter diferenciais competitivos é preciso estar sempre buscando novidades que agreguem valor para os clientes ou para a cadeia de negócios como um todo.

Dessa forma, o estudo realizado aponta uma série de elementos a serem considerados na busca de Alinhamento Estratégico da utilização da Internet e do CE. Verifica-se que ele envolve decisões não só tecnológicas mas organizacionais, em que devem ser consideradas variáveis do ambiente externo, como clientes, concorrentes, acesso a tecnologias...; variáveis do ambiente interno não só da área de TI, como infra-estrutura, governança, riscos envolvidos, como também da organização como um todo, por exemplo produtos e serviços, estrutura, recursos, capacidades; e de áreas específicas, como Marketing.

Vários fatores que contribuem para o Alinhamento das ações da Internet/CE foram identificados: visão estratégica dessas tecnologias; elaboração conjunta de estratégias por equipes multidisciplinares; avaliação e feedback constante com estratégias incrementais; e busca de sinergia na utilização das tecnologias, assim como estreita ligação com os negócios convencionais; e busca de atualização constante, entre outros elementos.

Espera-se que os resultados apresentados sejam úteis (veja síntese no Quadro 1), uma vez que esse referencial pode apoiar a formulação de estratégias de utilização e o processo decisório que envolve a escolha das funcionalidades de Internet e de Comércio Eletrônico, contemplando as diversas variáveis envolvidas nesse processo. Acredita-se que novas ferramentas e possibilidades de uso da Internet e do CE estão surgindo, como o Comércio Móvel (M-business); dessa forma, a longo prazo, um referencial que subsidie as decisões inerentes à utilização dessas tecnologias permanecerá válido. 


\section{Quadro 1: Fatores para o Alinhamento Estratégico da Utilização da Internet/CE}

FATORES QUE CONTRIBUEM PARA O ALINHAMENTO ESTRATÉGICO DA UTILIZAÇÃO DA INTERNET E DO COMÉRCIO ELETRÔNICO (CE)

- Visão estratégica das aplicações de Internet e CE e forte orientação para o mercado Consideração das diversas variáveis envolvidas nas decisões de uso da Internet/CE:

- Variáveis externas: perfil dos clientes, necessidades, possibilidade de acesso à tecnologia; Credibilidade da empresa junto à comunidade e clientes; perfil dos concorrentes e ofertas existentes no mercado; Infra-estrutura tecnológica etc.

- Variáveis do ambiente interno da empresa: produtos e serviços, estrutura, recursos e capacidades; infra-estrutura e governança da área de TI etc.

- Integração entre o planejamento organizacional, planejamento de TI e das ações de utilização da Internet e CE.

- Elaboração conjunta de estratégias e ações por equipes multidisciplinares.

- Planejamento incremental e dinâmico, avaliação e feedback constante com proveito da aprendizagem organizacional.

- Sinergia entre as diferentes aplicações de Internet/CE e integração de canais.

- Postura realista em relação aos investimentos em TI e CE.

- Busca de exploração das diferentes fontes de valor do e-business: complementaridade, novidade, lock-in e eficiência.

- Preservação de identidade única da empresa: negócios/estrutura convencional x virtual.

- Busca de inovação constante nas ações de Internet/CE.

Fonte: dados da pesquisa.

\section{ReferÊnCIAS Bibliográficas}

\section{ALBERTIN, A. L.}

Comércio Eletrônico: modelo, aspectos e contribuições de sua aplicação. 2. ed. São Paulo: Atlas, 2000. p. 276.

AMIT, R.;

ZOTT, C.

Value Creation in e-business. Strategic

Management Journal, [S.L.], v. 22., n. 6-7, p. 493-520, june/july 2001.

AUDY, J.;

LEDERER,A.;

BRATCHER, A.

Princípios da aprendizagem orga- nizacional aplicados ao planejamento de sistemas de informação: um estudo exploratório. In: ENCONTRO ANUAL DA ANPAD, 24., 2000, Florianópolis, Anais... Florianópolis: ANPAD. CD-ROM.

BENBASAT, I.;

GOLDSTEIN, D.K.;

MEAD, $\mathrm{M}$.

The case research strategy in studies of information systems. MIS Quarterly, Minneapolis-EUA, v.11, n.3, p.369-386, sep. 1987. 
BRODBECK, A.;

HOPPEN, $N$.

Alinhamento estratégico entre os Planos de Negócio e de Tecnologia de Informação: Modelo Operacional para Implementação. In: ENCONTRO ANUAL DA ANPAD, 26., 2002, Salvador, Anais... Salvador: ANPAD. CD-ROM.

Modelo de alinhamento estratégico para implantação dos Planos de Negócio e de Tecnologia de Informação. In: ENCONTROANUALDAANPAD, 24., 2000, Florianópolis, Anais... Florianópolis: ANPAD. CD-ROM.

BROWN, C. V.;

MAGILL, S.

Alignment of the IS functions with the enterprise: toward a model of antecedents. MIS Quarterly, Minneapolis-EUA, v. 18, n. 4, p. 371403, dec. 1994.

\section{CASTELLS, $\mathrm{M}$.}

The Internet Galaxy. 1. ed. New York: Oxford U.P. 2001, p.289.

CHAN, Y. E. et al.

Business strategic orientation, information systems strategic orientation and strategic aligment. Information Systems Research, Hanover Maryland-EUA, v. 8, n. 02, june 1997.

\section{CRONIN, M.}

The Internet Strategy handbook: lessons from the new frontier of business. 1. ed. Boston: Harvard Business School Press, 1996, p.296

\section{EISENHARDT, $\mathrm{K}$.}

Building theories from case study research. Academy of Management
Review, New York-EUA, v. 14, n. 4, p. 532-550, 1989.

\section{GASCOYNE, R.;}

OZCUBUKCU, K.

Corporate Internet Planning Guide.

1. ed. New York: Van Nostrand Reinhold, 1997, p. 320.

\section{GULATI, R.;}

GARINO, J.

Get the right mix of bricks \& clicks. Harvard Business Review, BostonEUA, v. 78, n. 3, p. 107-114, may/june 2000.

\section{HACKBARTH, G.;}

KETTINGER, W. J.

Building an e-business strategy. Information Systems Management Journal, New York-EUA, v. 17, n. 3, p. 78-93, July 2000.

\section{HENDERSON, J. C.;}

VENKATRAMAN, $\mathrm{N}$.

Strategic Alignment: leveraging information technology for transforming organizations. IBM Systems Journal, New York-EUA, v. 38, n. 2 e 3, p. 472-484, 1993.

\section{JACKSON, J.;}

CHANG, K.;

GROVER, V.

E-commerce strategy and corporate performance. In: AMERICAS CONFERENCE ON INFORMATION SYSTEMS, 8, 2002, Dallas-EUA, Anais... Dallas-EUA: AIS, 2002. p. 688-696. CD-ROM.

KALAKOTA, R.; ROBINSON, $M$.

E-business 2.0 - Roadmap for sucess.

1. ed. New York: Addison-Wesley, 2001, $520 \mathrm{p}$. 
KEARNS, G;

\section{LEDERER,A.}

Strategic IT alignment: a model for competitive advantage. In: INTERNATIONAL CONFERENCE ON INFORMATION SYSTEMS, 22., 2001, New Orleans-EUA. Proceedings... Atlanta-EUA: AIS. 2001. Disponível em: <http:// www.aisnet.org. $>$. Acesso em: 21 out. 2001. p. 1-12,

\section{LUFTMAN, J.}

Assessing Business-IT Alignment Maturity. Communications of the AIS. Atlanta-EUA, v. 4, art. 14, dec. 2000.

Competing in the information age. 1. ed. New York: Oxford, 1996. p. 432

\section{LUFTMAN, J.;}

PAPP, R.;

BRIER, T.

Enablers and inhibitors of BusinessITAlignment. Communications of the AIS. Atlanta-EUA, v. 1, art. 11, mar. 1999.

\section{LUFTMAN, J.;}

LEWIS, P.;

OLDACH, S.

Transforming the enterprise: alignment of business and Information technology strategies. IBM Systems Journal, New YorkEUA, v. 32, n. 1, p. 198-221, 1993.

\section{MINTZBERG, H.;}

QUINN, J. B.

O processo da estratégia. 1. ed. Porto Alegre: Bookman, 2001. p. 304.
NGAI, E.;

WAT, F.

A literature review and classification of Electronic Commerce Research. Information \& Management Journal, [S.L.], v. 39, n. 5, p. 415-429, mar. 2002.

PAPP, R.;

FOX, D.

Information Strategy Development: strategic alignment imperative. In: AMERICAS CONFERENCE ON INFORMATION SYSTEMS, 8, 2002. Dallas-EUA. Anais... Atlanta-EUA: AIS, 2002 p.1321-1325. CD-ROM.

PORTER, M.

Strategy and the Internet. Harvard Business Review, Boston-EUA, v. 79, n. 3, p. 62-78, mar. 2001.

\section{RAGHUNATHAN, M;}

MADEY, G.

EC Strategy Generator: a tool to formulate a firm's EC strategy. In: AMERICAS CONFERENCE ON INFORMATION SYSTEMS, 7, 2001, Boston-EUA. Proceedings... Atlanta-EUA: AIS, 2001, p. 934-939. CD-ROM.

REICH, B. H.;

BENBASAT, I.

Factors that influence the social dimension of alignment between business and information technology objectives. MIS Quartely, Minneapolis-EUA, v. 24, n. 1, p. 81113, mar. 2000.

Measuring the linkage between Business and Information Technology objectives. MIS Quarterly, Minneapolis-EUA, v. 20, n. 1, p. 55-81, mar. 1996. 
REILLY, G;

ROZWELL, C.;

LEHONG $\mathrm{H}$.

Selecting and prioritizing E-business Projects. Gartner Group Research Note, [S.L.], n. 5, p. 1-4, sep. 2001.

\section{ROZWELL, C.}

Strategy and E-business: Fast Friends or the Same Thing? Gartner GroupResearch Note, [S.L.], n. 21, p. 1-5, sep. 2001.

\section{SEGARS, A.;}

GROVER, V.

strategic information systems planning success: an investigation of the construct and its measurement. MIS Quarterly, Minneapolis-EUA, v. 22, n. 2, p. 139-163, june 1998a.

\section{TENG J.}

Strategic Information Systems Planning: Planning System Dimensions, Internal Coalignment, and Implications for Planning Effectiveness. Decision Sciences, Oxford, v. 29, n.2, p.303-346, 1998b.
TURBAN, E. et al.

Electronic Commerce: a managerial perspective. 1. ed. New Jersey: Prentice-Hall, 1999. p. 512.

\section{VENKATRAMAN, $\mathrm{N}$.}

Five steps to a Dot-Com strategy: how to find your footing on the web. Sloan Management Review, Cambridge-Massachusetts-EUA, v. 41, n. 3, p. 15-28, spring 2000.

\section{WISEMAN, C.}

Strategy and computers: Information Systems as Competitive Weapons. . ed. Homewood-EUA, Dow-Jones Irwin, 1985, 320 p.

YIN, R.

Estudo de caso: planejamento e métodos. 2. ed. Porto Alegre: Bookman, 2001. p. 212.

\section{ZVIRAN, M.}

Relationships between organizational and Information Systems objectives: some empirical evidence. Journal of Management Information Systems, New-York-EUA, v. 7, n.1, p. 65-84, summer 1990. 